\title{
Reflexões Sôbre Problemas e Tendências da Administração Para o Desenvolvimento
}

ERVIN L. PETERSON

Tradução de Raimundo Xavier de Menezes

Entre 27 de outubro e 6 de novembro passados a Organização das Nações Unidas realizou em Washington, D.C., nos Estados Unidos da América, um Seminário Inter-regional sôbre Utilização de Técnicas Modernas de Gestão por Parte da Administraçăo Pública dos Países em Desenvolvimento, tendo, na reuniăo de abertura e na qualidade de anfitrião, o Sr. Ervin L. Peterson, Assessor Representante do Administrador da Assistência Técnica da Agência para o Desenvolvimento Internacional (A.I.D.) do Departamento de Estado, pronunciado o discurso que vem a seguir traduzido, cuja leitura será altamente proveitosa para todos aquêles que se preocupam com a moderna problemática administrativa. Dêsse conclave participaram 38 países, várias organizações internacionais e repartições comprometidas em programas de desenvolvimento, cujos representantes, juntamente com técnicos especialmente convocados, examinaram 59 trabalhos e aprovaram informe a ser brevemente publicado.

\section{Dr. Wu *, Senhoras e Senhores}

Seja-me permitido, em primeiro lugar, dar-Ihes as boas-vindas. Sentimo-nos honrados com a presença aqui de mais de 70 personalidades - funcionários públicos, peritos em administração, diretores de escolas e institutos de administração, administradores de emprêsas privadas ou públicas - tôdas engajadas em atividades nas áreas nacional ou internacional.

A grande experiência e profissionalismo aqui representados autorizam- nos esperar que êste seja um seminário altamente produtivo, o qual dê continuidade à troca de experiência que a Divisão de Administração Pública da Organização das Naçōes Unidas tem tão hàbilmente conseguido levar avante. Nós na Agência para o Desenvolvimento Internacional (A.I.D.) consideramos os conceitos e documentos provenientes da Divisão de Administração Pública da ONU particular-

* Dr. Chi-Yuen Wu, Diretor da Divisåo de Administraçắo Pública da Organizaçăo das Naçoes Unidas (Nota do Tradutor). 
mente auxiliadores em nossos trabaIhos.

Ao penetrarmos na Segunda Década do Desenvolvimento, afigura-se-me que testemunhamos mudanças significativas no estilo da cooperação técnica. Para os anos vindouros prevejo, como interêsse central da cooperação técnica, maior focalização no bemestar humano. Espero maiores progressos no esfôrço cooperativo por parte das organizações e órgãos prestadores de assistência técnica. Equipes internacionais e interdisciplinares estarão procurando meios mais eficazes de aceleração do crescimento econômico e de expansão do bem-estar social. Tais equipes trabalharão cada vez mais sob os auspícios de instituições atuantes na área internacional, de modo crescente colocarão ênfase no compartilhamento de experiência, principalmente para adaptar a novas circunstâncias bem sucedidos programas de desenvolvimento. Conseguirão combinar contribuições profissionais, representando disciplinas e pontos de vista variados. Enfrentarão muitos desafios, entre os quais destaco a necessidade de habilitar-se a conseguir compreensão e comunicação interprofissionais.

A Segunda Década do Desenvolvimento também trará um nôvo estilo à administração para o desenvolvimento. Uma era de rápidas inovações tecnológicas e mutações sociais requererá certamente uma administração capaz de adaptar-se a situações cambiantes. $O$ uso eficiente de recursos destinados aos programas de desenvolvimento exigirá uma administração imaginativa e modernizante que seja dinâmica, voltada para o futuro, capaz de auto-avaliar-se - uma administração disposta a modificar-se e a assumir o aumento de responsabilidades.

No processo do desenvolvimento, como Dr. Wu já afirmou por escrito, a carga administrativa está continuamente ultrapassando a capacidade administrativa. Deficiências de administração constituem, com freqüência, causa de fiasco na implementação de planos de desenvolvimento. $O$ desenvolvimento é um processo ininterrupto em todos os países. Assim sendo, a capacidade administrativa deve ser sempre aumentada à medida que o desenvolvimento se processa.

A administração constitui uma dimensão de tôda emprêsa humana, sendo, contudo, particularmente importante nas emprêsas ligadas ao desenvolvimento, isto por duas razöes. Em primeiro lugar, porque desenvolvimento exige a mobilização $\theta 0$ uso eficiente de recursos parcos e isto só se consegue com boa administração, $e$, em segundo lugar, porque desenvolvimento implica mutação. $O$ afastamento dos existentes padrões de atividade requer inevitàvelmente alterações de natureza organizacional e nos procedimentos administrativos.

A pressão sôbre a capacidade administrativa decorre em parte da mudança planificada, em parte do grande aumento da fermentação social e tecnológica que afeta todos os paises. Consideremos alguns exemplos de inovaçöes tecnológicas. Alta fertilidade de diferentes espécies de arroz, trigo, e de outras gramíneas ocasionou a "revolução verde" em muitos países em desenvolvimento. A engenharia genética poderá produzir fenômenos semeIhantes, como, por exemplo, alto teor protéico dos grãos. Necessita-se de 
um sistema que dê continuidade $\theta$ intensifique o impeto produtivo já alcançado e consiga distribuir o acréscimo de produção obtido. A tecnologia industrial acarretou inúmeros desenvolvimentos. A tecnologia no campo das comunicações e transportes reduziu o espaço e o tempo. A tecnologia referente à saúde e à educação promete uma vida mais completa para todos os povos em tôda parte. Em graus variáveis, tôdas estas inovações tecnológicas implicam necessidades de novos arranjos organizacionais e de novos mecanismos administrativos.

As mutaçōes sociais também puxam pela capacidade administrativa existente. Considere-se o efeito do aumento populacional na expansão das exigências educacionais. Considere-se a consequeência da urbanização - essa incessante onda humana movendo-se para as cidades, e as respectivas repercussões no mercado de trabalho sôbre habitação, transporte e relações politicas e sociais.

Alterações sociais e tecnológicas estão ocorrendo em todos os países, criando grandes problemas para politicos, administradores e empresários particulares; mas de igual modo oferecendo múltiplas oportunidades. Nos detalhes há variações de país para país. Por outro lado, estamos bem cientes de que as condições num ambiente não respondem necessàriamente aos estímulos tidos como eficazes em outro. Por estão razão - entre muitas outras - a troca recíproca de experiência e sua mútua avaliação pode ser de inestimável valor para todos os agentes promotores do desenvolvimento. Uma das conquistas principais dêste Seminário será proporcionar êsse intercâmbio mútuo.
Tenho-me referido à mutação. Mutação é uma condição da vida. Contudo, no contexto desenvolvimentista parece-me que ela deve ser deliberada $\theta$ inteligentemente planejada. A administração para o desenvolvimento relaciona-se com atos destinados a provocar a mudança planejada que se busca. Provocação de mudança requer organizaçōes, isto é, corpos possuidores de certos recursos materiais e humanos, e, além disso, capazes de comandar a aplicação de recursos estranhos a êles próprios ou de seu uso beneficiar-se. A administração consiste na proposital combinação, direção e aplicação de tais recursos.

Os administradores desenvolvem e utilizam certas técnicas e metodologias. A medida que ocorrem alterações no ambiente onde atua a organização, deve a administração adaptarse às condições em transição. Recursos disponiveis podem carecer de remanejo, técnicas e metodologias podem precisar ser reformuladas. Caso uma organização tenha funções novas ou ampliadas, é provável que sua reestruturação se imponha. Orientação, direção e decisão constituem responsabilidades administrativas.

Minha tese é que a administração deve ser dinâmica. Deve responder a novas e acrescidas exigências surgidas nas respectivas organizaçōes. Também a administração moderna se tem modificado. Técnicas e metodologias novas ou reformuladas estão aí. As mudanças ambientais têm constituído o fator de estímulo. Alguns desenvolvimentos podem ser alistados:

- organizações mult i-funcionais mais amplas para emprêsas econômicas e serviço público; 
- elaboração de novos instrumentos para obter, guardar, processar, manipular e divulgar informações;

- novas técnicas e metodologia para mensuração de desempenho;

- inovações na ciência do comportamento;

- nova compreensão das inter-relações no tocante à filosofia-política-programa-projeto;

- melhor compreensão das relações reciprocas entre setores econômicos;

- um despertar para a noção de sistemas (econômico-político-ecológico-agrícola-educacional para mencionar uns poucos).

A lista não é completa, porém suficiente para ilustrar que a administração tem sofrido, de modo significativo, o impacto das transformações sociais e tecnológicas.

Dadas as dinâmicas das transformações sociais e da moderna administração, surge-nos o problema de como poderemos melhor utilizar as técnicas da moderna administração para efeito do desenvolvimento. Como poderemos tirar vantagem dos novos instrumentos administrativos para acelerar o passo e ampliar os benefícios do desenvolvimento? De que modo nos será possivel adaptar a experiência e as técnicas administrativas de outros países para ajudar-nos a resolver os nossos problemas de desenvolvimento? Como poderemos descobrir se técnicas bem sucedidas em um meio são apropriadas em outro?

Respostas parciais podem obter-se através do estudo das limitações e possibilidades teóricas das técnicas administrativas. Respostas mais com- pletas podem advir do aprendizado sôbre o uso efetivo de técnicas partlculares. O estudo não deve parar. Entretanto, os apelos à organização e a sua administração não devem cessar enquanto os estudos prosseguem. Os resultados dos estudos devem alimentar o processo administrativo à medida que se tornam válidos e disponiveis. $\mathrm{A}$ validade consagra-se pelo uso. A administração moderna deve conter um elemento de pragmatismo. Que funciona? De que modo podem ser melhor combinados e aplicados os recursos disponiveis para obtenção dos resultados desejados? Avanços proveitosos em administração ocorrem no terreno experimental das operações.

Meias-verdades de três espécies prejudicam tais avanços. Em primeiro lugar, de natureza setorial, aquelas que asseguram, por exemplo, só um educador poder contribuir com algo útil no campo da administração educacional; em segundo lugar, de natureza local, aquelas que afirmam que as condições enfrentadas são tão peculiares que a aplicação de experiência estranha não pode ser relevante; e em terceiro lugar, de cunho administrativo, aquelas que ensinam ser a chave para o êxito de qualquer empreendimento desenvolvimentista o uso da mais moderna técnica de administração, sem se preocupar com adaptações na área local ou setorial.

Todos nós, entretanto, estamos coIhendo ensinamentos sôbre o papel da administração no desenvolvimento e na assistência ao desenvolvimento. Êste Seminário e outros eventos semelhantes no futuro aumentarão nossa compreensão e à medida que esta se amplie, melhoraremos nossos padrōes de desempenho. 
Gostaria, agora, de mencionar uma facêta do trabalho levado a cabo pelo Bureau de Assistência Técnica da A.I.D., a qual pode ser de interêsse para os Senhores. No ano passado, nosso Escritório de Administração para - Desenvolvimento procurou identificar problemas-chave na administração do desenvolvimento, que se afigurassem comuns ao processo desenvolvimentista. Esta análise contou com a contribuição de peritos oriundos dos paises em desenvolvimento e de instituições internacionais, bem como de outros setores da Agência, que recorreram a várias fontes documentais.

Uma constatação mostra a existêncla, em quase todos os países, de centros de formação de professôres em administração. Noto que muitas dessas escolas e institutos de administração têm representantes neste Seminário e estão provendo, não só uma corrente contínua de administradores treinados, como uma base indispensável para maiores avanços na educação administrativa.

Outra constatação posta em relêvo refere-se à necessidade de aumento do número e da qualidade dos administradores comprometidos na área do desenvolvimento. A idéia de progresso profissional pela vida a fora sugere um contínuo aperfeiçoamento na qualidade do desempenho administrativo.

Mais outra constatação destacou a necessidade particular de afirmar que os conhecimentos e técnicas de administração, e o treinamento de que participam, têm grande importância no atendimento das exigências de adaptação com que se defrontam aquêles que administram programas de desenvolvimento ou provêem serviços públicos.

Concluída a análise inicial, três problemas-chave foram isolados para merecer atenção contínua por parte do Bureau de Assistência Técnica. São êles:

1) a insuficiência de mão-de-obra administrativa para fazer face às exigências determinadas pelo crescimento e pela modernização;

2) a falta de capacidade de ação local. Isso abrange deficiências na estrutura organizacional que impedem aos órgãos centrais prestar serviços no interior e também incapacidade administrativa no que tange às organizações de âmbito local;

3) a necessidade quanto a organizações e instituições relevantes para o desenvolvimento, com capacidade de administrar, eficientemente, programas de desenvolvimento e adaptar-se às mutações ambientais.

O trabalho nessas três áreas de problemas é uma parte apenas do esfôrço despendido pela A.I.D. para proporcionar aperfeiçoamento administrativo, que é uma componente do processo desenvolvimentista. Há outros programas em ação conduzidos pelos Bureaux Regionais e Missões no Estrangeiro, que mantêm colaboração direta com os governos e instituições dos paises em desenvolvimento ou cooperam com instituições regionais e multilaterais. A investigação e análise por nós até aqui levadas a efeito nas áreas do desenvolvimento institucional, das exigências organizacionais e das necessidades administrativas, no 
que se relacionam com o desenvolvimento ou com a assistência ao desenvolvimento, servem para sublinhar nosso interêsse neste Seminário, na mútua e colaboradora troca de experiência e no trabalho em conjunto com nossos colegas no campo de desenvolvimento, de modo que o esfôrço de todos nós se torne mais eficiente e produtivo. Não afirmamos, certamente, possuir resposta para as muitas questões que se nos apresentam. Estamos tentando aprender à medida que caminhamos. Assim sendo, acolhemos a oportunidade de nos unirmos nesta recíproca troca de experiência e intercâmbio de opiniões.

Todos nós reconhecemos que mudança é uma condição de vida. O problema que enfrentamos em conjunto é se podemos ou não dirigir e acelerar a mudança, de modo que nos torne a vida uma experiência nobilitante e enriquecedora. Estamos cons- cientes da grande fertilidade de nosso planeta. Nossos esforços coletivos são dirigidos no sentido de tornar essa fertilidade igualmente ao alcance de todo ser humano, não importa onde viva.

Se bem que nossa atenção neste Seminário esteja sendo dirigida essencialmente para um elemento de nosso esfôrço, creio tratar-se de coisa importante. Nossas instituições, nossas organizações só poderão ser completamente eficientes quando sua administração se conformar com os mais elevados padrões de excelência e capacidade. Dêsse modo, em conjunto, ampliemos mais ainda nossa compreensão da administração, de seus princípios, de suas técnicas e de sua metodologia. Considero isto como o grande empuxo que êste Seminário pode proporcionar. Calorosamente desejamos a cada um dos presentes boas-vindas ao trabalho e pleno êxito em suas deliberações. 